УДК 331.101 .52

$10.17213 / 2075-2067-2021-3-182-190$

\title{
РАЗРАБОТКА ОРГАНИЗАЦИОННО-ЭКОНОМИЧЕСКОГО МЕХАНИЗМА УПРАВЛЕНИЯ НАУЧНО-ИССЛЕДОВАТЕЛЬСКОЙ ДЕЯТЕЛЬНОСТЬЮ НАЦИОНАЛЬНЫХ ИССЛЕДОВАТЕЛЬСКИХ УНИВЕРСИТЕТОВ
}

\section{(C) 2021 г. М. А. Киселева}

Национальный исследовательский университет «МЭИ», г. Москва, Россия

Целью исследования является разработка организационно-экономического механизма управления научно-исследовательской деятельностью наџионального исследовательского университета, отличающаяся от сущуествующих разработок возможностью очченки научно-исследовательской деятельности на основе анализа показателей эффрективности деятельности научных групп.

Методологическую базу исследования составили методы: диалектический, научного познания и частные научные (анализ, синтез, сравнение, логический и системно-структурный анализ, формализация, анализ нормативно-правовых документов), моделирование.

Результаты исследования помогут формировать научные группь для подачи заявок и выполнения проектов в области научно-технической и грантовой деятельности начиональных исследовательских университетов.

Перспектива исследования. Модернизированный организаџионно-экономический механизм в дальнейшем сможет оптимизировать другие составляющие научно-исследовательской деятельности университетов.

Ключевые слова: национальные исследовательские университеты; субъекты научноисследовательской деятельности; заявочная активность; научно-техническая и грантовая деятельность; научные группь;; организационно-экономический механизм.

\section{DEVELOPMENT OF AN ORGANIZATIONAL AND ECONOMIC MECHANISM FOR MANAGING THE RESEARCH ACTIVITIES OF NATIONAL RESEARCH UNIVERSITIES}

\section{(C) 2021 M. A. Kiseleva}

\section{National Research University «MPEI», Moscow, Russia}

The purpose of the study is to develop an organizational and economic mechanism for managing the research activities of the national Research University, which differs from the existing developments in the ability to evaluate research activities based on the analysis of performance indicators of research groups.

The methodological base of the study was made up of methods: dialectical scientific knowledge and private scientific (analysis, synthesis, comparison, logical and system-structural analysis, formalization, analysis of legal documents), modeling.

The results of the study will help to form research groups for submitting applications and implementing projects in the field of scientific, technical and grant activities of national research universities. 
Research perspective. The modernized organizational and economic mechanism will be able to optimize other components of the research activities of universities in the future.

Key words: national research universities; subjects of research activity; application activity; scientific and technical and grant activities; research groups; organizational and economic mechanism.

Введение. В стратегии пространственного развития Российской Федерации до 2025 года [1] одним из приоритетных направлений развития науки является ее обеспечение высокопрофессиональными техническими кадрами с набором компетенций, способных решать меняющиеся запросы реального сектора экономики. Наука должна отвечать на вызовы глобального мира. Таким образом, возникла необходимость для скорейшего решения возникающих критических проблем в ее управлении. Эту проблему могут решать национальные исследовательские университеты (НИУ) Российской Федерации. На данный момент в качестве основного метода оценки результативности субъектов научно-исследовательской деятельности (НИД) НИУ используются только наукометрические показатели индивидуальных субъектов, такие как индекс цитирования, индекс Хирша, экспертные оценки и т.д. Однако для оценки заявочной активности в области научно-технической и грантовой деятельности не учитывается результативность научных групп как единого целого. Кроме того, наблюдается отсутствие комплексных механизмов управления НИД национальных исследовательских университетов, где отражалась бы значимость созданных научных групп и их оценка, в связи с чем возникает острая необходимость в обеспечении грамотного формирования научных групп для развития НИД как первостепенного показателя его статуса, а также их дальнейшего участия в развитии инновационного экономического потенциала страны.

Целью исследования является разработка организационно-экономического механизма управления научно-исследовательской деятельностью национального исследовательского университета, отличающаяся от существующих разработок возможностью оценки научно-исследовательской деятельности на основе анализа показателей эффективности деятельности научных групп.
Методологическую базу исследования составили следующие методы: диалектического научного познания и частные научные (анализ, синтез, сравнение, логический и системно-структурный анализ, формализация, анализ нормативно-правовых документов), моделирование.

За последние 10 лет численность исследователей по техническим наукам по Российской Федерации сокращается. Такую тенденцию можно проследить на рисунке 1. В Росстате данный показатель состоит из трех составляющих: численность исследователей, не имеющих степени, численность кандидатов наук и докторов наук [2]. В 2019 году все эти составляющие существенно сократились. Численность исследователей, не имеющих ученой степени, снизилась на 2,01\%, кандидатов наук - на $1,75 \%$, докторов наук на $3,02 \%$.

Численность исследователей по экономическим наукам в Российской Федерации также постепенно сокращается. Это можно увидеть на рисунке 2. Так, например, в 2019 году все эти показатели существенно снизились. Численность исследователей, не имеющих ученой степени, снизилась на 0,95\%, кандидатов наук - на $0,96 \%$, докторов наук на $0,35 \%$. Учитывая такую тенденцию, автор выявляет необходимость в разработке мер по привлечению, стимулированию и «выращиванию» наиболее перспективных сотрудников организаций, выполняющих НИОКР.

Автором отмечается возможность получения грамотных специалистов, обладающих уникальными навыками, способностями, умениями и достижениями в какой-либо конкретной области деятельности, а также появления инноваций, которые должны начинаться в первую очередь с самого развития научно-исследовательской деятельности национальных исследовательских университетов. Так как именно с этой деятельности начинается весь цикл производства и формиро- 
вания инноваций (полезных моделей, открытий, опытных образцов, рационализаторских решений и баз данных) и тех, кто сможет ее производить.

Чтобы увеличить количество таких специалистов, необходимо привлекать, мотивировать и заинтересовывать потенциальных субъектов научно-образовательного процесса заниматься научно-исследовательской деятельностью в национальных исследовательских университетах с помощью их формирования в научные группы. Существуют различные трактовки понятия «научных групп» различными университетами, представленными на рисунке 3.
Новгородский государственный университет имени Ярослава Мудрого (НовГУ) [3] дает следующее описание НГ: для выполнения каждой научно-исследовательской, опытно-конструкторской, опытно-технологической, проектной, конструкторской или технологической работы в структуре университета приказом формируется временный творческий коллектив (научная группа), назначается научный руководитель и при необходимости - ответственный исполнитель. Обязательным условием выполнения НИР в рамках государственного задания служит наличие в составе научной группы аспирантов и студентов НовГУ.

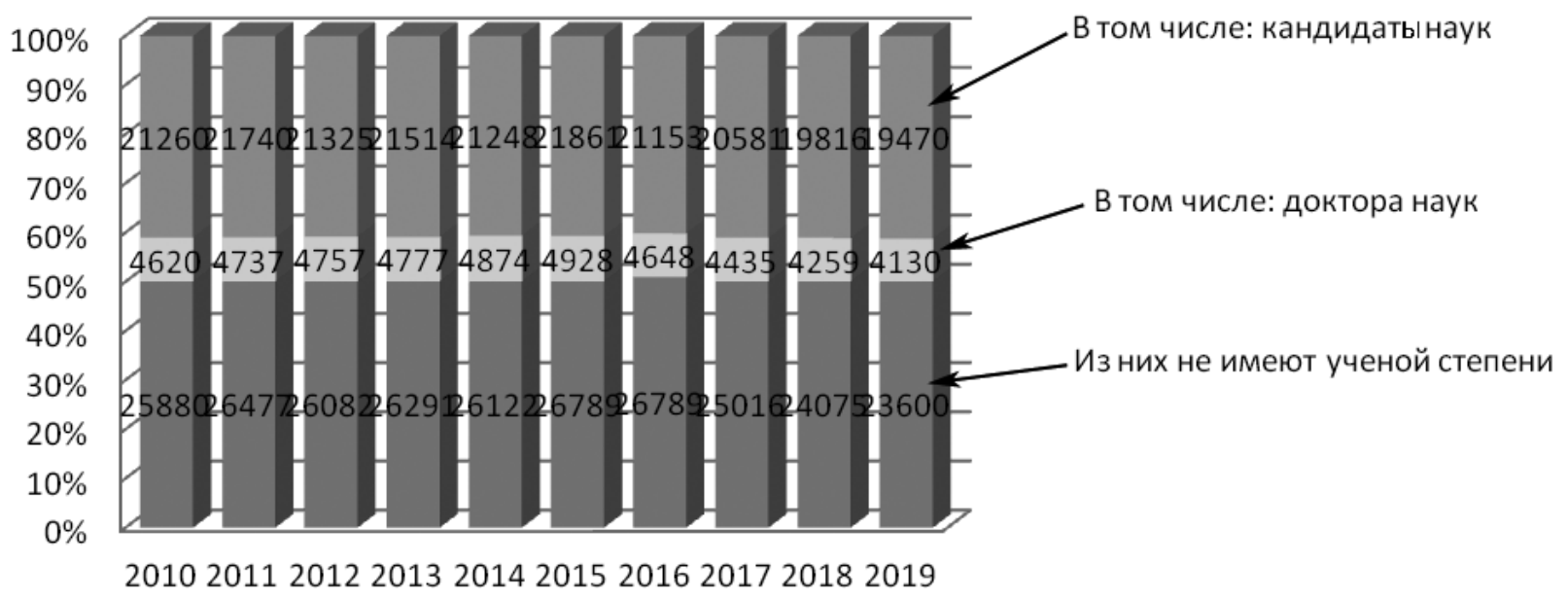

Рис. 1. Численность исследователей по техническим наукам в Российской Федерации (разработано автором на основании [2])

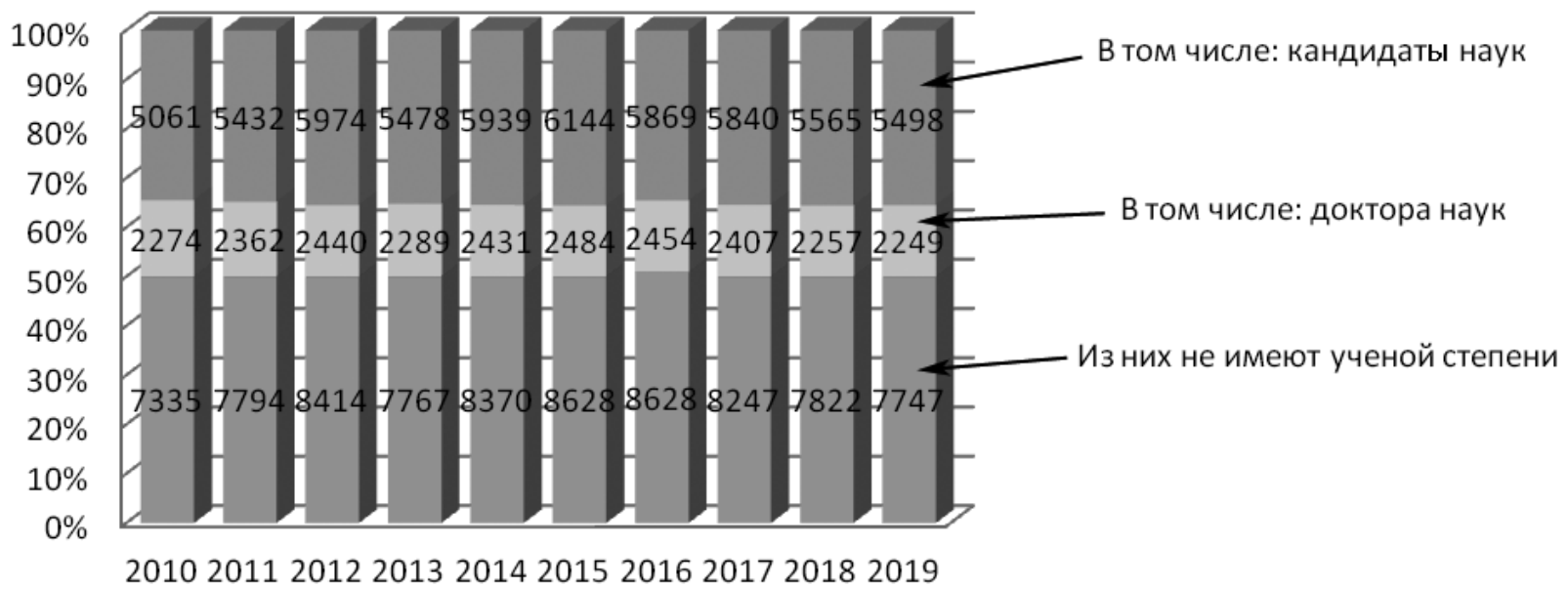

Рис. 2. Численность исследователей по экономическим наукам в Российской Федерации (разработано автором на основании [2]) 
МГТУ им. Баумана [4] определяет научные группы как коллектив, выполняющий комплекс следующих задач:

- эффективное использование научного потенциала МГТУ им. Н.Э. Баумана для проведения научно-исследовательских работ;

- развитие фундаментальных научных исследований в соответствии с профилями подготовки специалистов в университете;

- развитие научного и научно-технического сотрудничества с вузами, научными, проектно-конструкторскими организациями, предприятиями и фирмами, зарубежными партнерами в целях усиления интеграционных процессов образования, науки и промышленности.

Научные группы МАИ [5] определяются как коллектив, реализующий научно-исследовательские проекты в области конструирования авиакосмической техники, перспективных двигательных и энергетических установок, беспилотных летательных аппаратов, технологий гиперзвука, систем искусственного интеллекта и др.

НИЯУ МИФИ [6] использует определение «Инжиниринговый центр» вместо научной группы. ИЦ НИЯУ МИФИ (Инжиниринговый центр НИЯУ МИФИ) - структурное подразделение Национального Исследовательского Ядерного Университета МИФИ, в задачи которого входит управление перспективными научными исследованиями молодых ученых вуза.

НИУ «МЭИ» [7] определяет научные группы как творческий коллектив сотрудников, аспирантов и студентов НИУ «МЭИ», объединившихся в рамках научно-технической деятельности для развития научного потенциала НИУ «МЭИ», поддержания действующих и создания новых научных школ, обеспечения кадрового воспроизводства научно-педагогических работников НИУ «МЭИ», для выполнения НИОКТР, формирования портфеля заказов, подготовки заявок на объекты интеллектуальной собственности, подготовки статей и докладов, подготовки кадров высшей квалификации, осуществления экспертной деятельности.

K положительным сторонам научных групп в университете можно отнести наличие в составе научных групп не менее $50 \%$ молодежи (студентов, магистрантов, аспирантов). Кроме того, при работе в группе уменьшается риск принятия ошибочного решения и опасность того, что в поле зрения не попадут некоторые важные факты.

К главным недостаткам научных групп можно отнести такие факторы, как:

— отсутствие результативности;

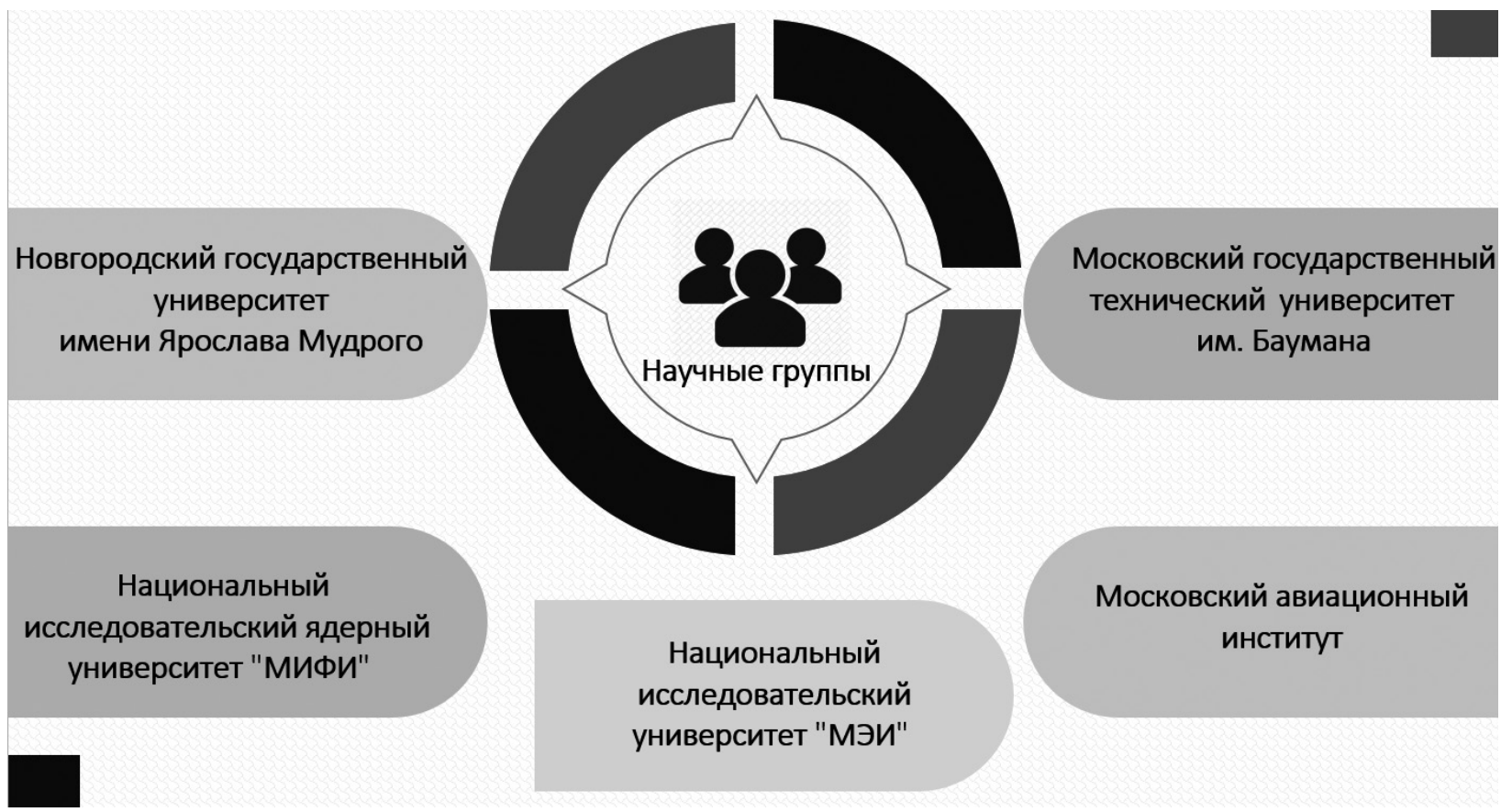

Рис. 3. Примеры университетов, трактующих различные понятия и задачи «научных групп» 


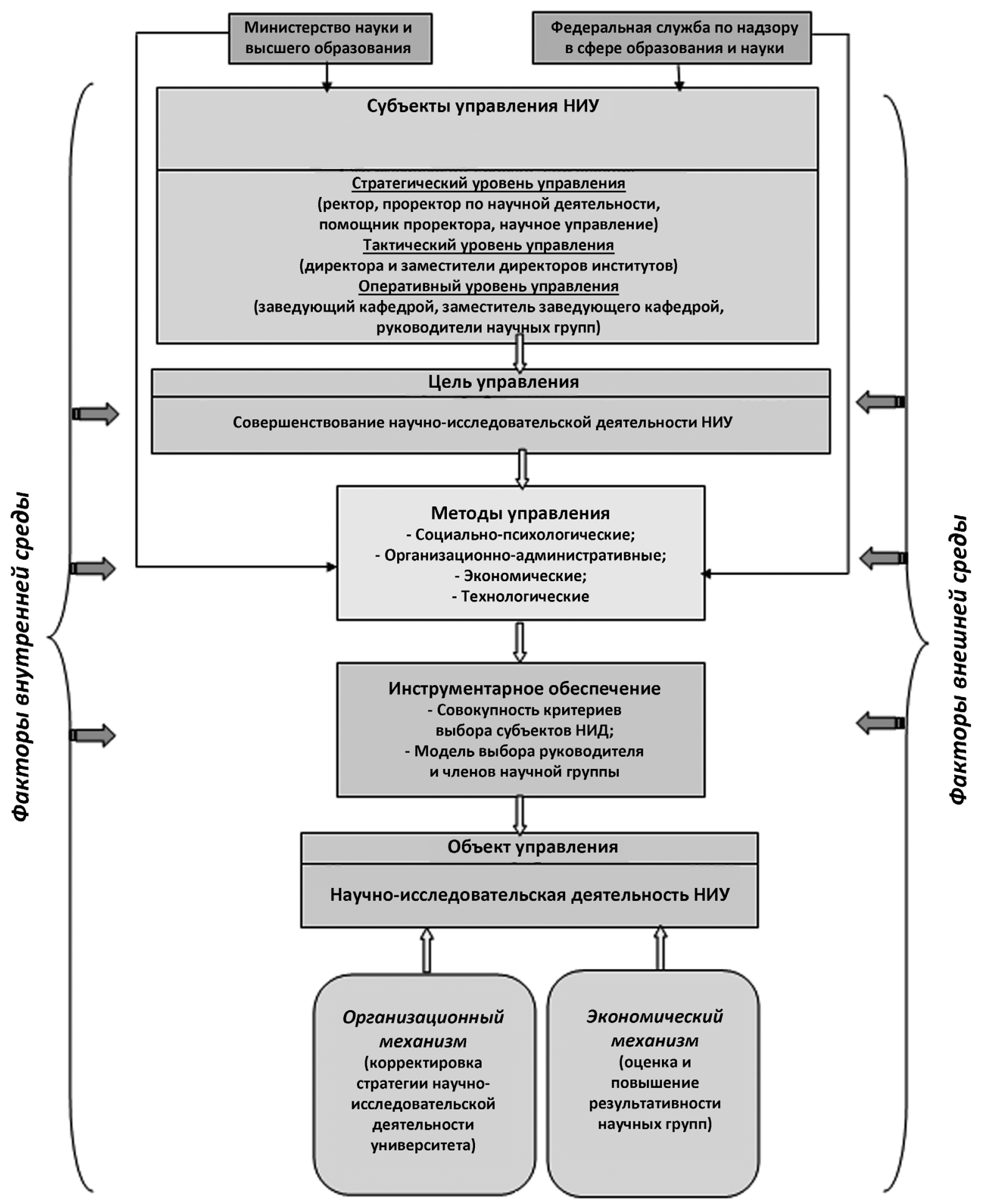

Рис. 4. Организационно-экономический механизм управления научно-исследовательской деятельностью в университете (разработано автором на основе [8]) 
- отсутствие взаимодействия с другими подразделениями;

- отсутствие в научных группах научного задела (совокупность новых результатов интеллектуальной деятельности в сфере науки и техники).

В связи с проведенным анализом в рамках исследования разработан организационно-экономический механизм (ОЭМ) [8] управления научно-исследовательской деятельностью национального исследовательского университета. Организационно-экономический механизм управления научно-исследовательской деятельностью в университете представлен на рисунке 4.

Проблема управления научно-исследовательской деятельностью в университете видится в том, что при формировании научных групп их деятельность часто носит формальный характер и не связана между собой. Например, сроки и количество подач заявок по проекту, их публикационная активность носят лишь краткосрочный характер. Таким образом, автором сформирован ОЭМ, целью управления которого будет являться совершенствование научно-исследовательской деятельности национального исследовательского университета $[9,10]$.

Рассмотрим структуру организационноэкономического механизма управления научно-исследовательской деятельностью национальных исследовательских университетов.

Объектом управления в организационноэкономическом механизме выступает научноисследовательская деятельность.

Внешними субъектами управления ОЭМ являются Министерство науки и высшего образования, а также Федеральная служба по надзору в сфере образования и науки.

Внутренними субъектами управления национальным исследовательским университетом в предложенном механизме выступают:

- стратегический уровень управления ректор, проректор по научной деятельности, помощник проректора, научное управление;
— тактический уровень управления — директора и заместители директоров институтов;

- оперативный уровень управления заведующий кафедрой, заместитель заведующего кафедрой, руководители научных групп.

На наш взгляд, наиболее конкретно организационную сторону ОЭМ [11] раскрывают такие методы, как:

1) отражение и проверка результатов НИД в индивидуальных планах сотрудников (организационно-административный метод);

2) повышение баллов в системе стимулирования за НИД (КРІ) (экономический метод);

3) продление контракта с сотрудниками (организационно-административный метод);

4) обновление и расширение материально-технического обеспечения НИУ (технологический метод);

5) присуждение именных наград или грамот Министерством науки и высшего образования (социально-психологический метод).

Оценка внутреннего воздействия на предлагаемый организационно-экономический механизм управления научно-исследовательской деятельностью в университете производится с помощью матрицы SNW [12] (сильные, слабые и нейтральные стороны). Матрица SNW представлена в таблице 1 .

Оценка внешнего воздействия на предлагаемый организационно-экономический механизм управления научно-исследовательской деятельностью в университете производится с помощью матрицы PESTEL [12] (политические, экономические, социо-культурные, технологические, правовые и экологические воздействия). Матрица PESTEL представлена в таблице 2.

Рассмотрим все перечисленные факторы более подробно [12].

P (Политические факторы) - налоги, устанавливаемые органами власти, правовые и регулирующие вмешательства в деятельность рынка.

E (Экономические факторы) - общий макроэкономический фон, в том числе эконо-

\section{Матрица SNW}

Таблица 1

\begin{tabular}{|l|l|l|}
\hline S & N & W \\
\hline (Сильные стороны) & (Нейтральные стороны) & (Слабые стороны) \\
\hline
\end{tabular}




\section{Матрица PESTEL}

\begin{tabular}{|l|l|l|}
\hline P & E & S \\
\hline (Политические факторы) & (Экономические факторы) & (Социо-культурные факторы) \\
\hline T & Е & L \\
\hline (Технологические факторы) & (Экологические воздействия) & (Правовые факторы) \\
\hline
\end{tabular}

мический рост, инфляция, процентные ставки и обменные курсы.

$\mathrm{S}$ (Социокультурные факторы) - общий социальный фон, в том числе тренды, относящиеся к населению, типы потребления и распределение населения по возрастам.

Т (Технологические факторы) - тренды в НИОКР и инновациях, влияющие на продукцию и производство, а также угрозы со стороны продуктов-субститутов.

Е (Экологические факторы) - тренды, связанные с погодой и климатом, влияние климатических изменений на операции университета.

L (Правовые факторы) - тренды в законодательной деятельности, влияющие на университет и принимаемые там решения, в том числе относящиеся к найму персонала, созданию среды, обеспечивающей сохранение здоровья и безопасность труда, а также антимонопольная деятельность, защита прав потребителей, достаточность капитала у финансовых учреждений и законы об управлении.

Разрабатываемый механизм должен выполнять ряд функций:

- планирование показателей научно-исследовательской деятельности национального исследовательского университета;

- организация научно-исследовательской деятельности национального исследовательского университета;

- мотивация сотрудников и обучающихся для выполнения научно-исследовательской деятельности;

- контроль за выполнением показателей научно-исследовательской деятельности и сравнение фактических показателей с запланированными;

- координация выполнения научно-исследовательской деятельности ответственными лицами на всех этапах ее выполнения.
С помощью предложенного организационно-экономического механизма активизируется работа научных групп и как следствие сама научно-исследовательская деятельность университета.

Данный механизм опирается на следующие принципы:

- принцип коммуникаций;

- принцип единства управления и самоуправления;

— принцип научности;

- принцип целостности и системности;

- принцип взаимосвязи единоначалия и коллегиальности;

- принцип преемственности;

- принцип интеграции;

- принцип целенаправленности;

- принцип иерархичности;

- принцип ответственности;

- принцип реактивности.

Перечисленные принципы служат методическим фундаментом развития стратегии, приводящей к развитию научно-исследовательской деятельности университета.

Заключение. Таким образом, в исследовании решена задача совершенствования управления научно-исследовательской деятельностью национальных исследовательских университетов на основе привлечения потенциальных субъектов к этой работе и формирования их в научные группы. Сoвершенствование управления научно-исследовательской деятельностью определяется на базе оценки и повышения эффективности деятельности научных групп для национальных исследовательских университетов как одного из главных показателей деятельности вуза. Решение указанной задачи представлено определенными методами и инструментами, которые прописаны в организационно-экономическом механизме. Примерами выступают 
модель выбора руководителя и членов научной группы, а также совокупность критериев выбора субъектов научно-исследовательской деятельности $[9,10]$.

\section{Литература}

1. Стратегия пространственного развития РФ на период до 2025 г. (утверждена распоряжением Правительства РФ №207-р от 13.02.2019) // Справочно-правовая система «Консультант Плюс».

2. Федеральная служба государственной статистики [Электронный ресурс] / Признаки НИУ. - Режим доступа: http://www.edu.ru (Дата обращения: 25.03.2021).

3. Портал Новгородского государственного университета имени Ярослава Мудрого [Электронный ресурс] / Научные группы. Режим доступа: https://www.novsu.ru/ (Дата обращения: 01.04.2021).

4. Портал Московского технического университета имени Н.Э. Баумана [Электронный ресурс] / Научные группы. - Режим доступа: https://bmstu.ru/ (Дата обращения: 01.04.2021).

5. Портал Московского авиационного института (национальный исследовательский университет) [Электронный ресурс] / Научные группы. - Режим доступа: https://mai.ru/ common/ (Дата обращения: 01.04.2021).

6. Портал Национального исследовательского ядерного университета МИФИ [Электронный ресурс] / Научные группы. - Режим доступа: https://mephi.ru/sveden/common (Дата обращения: 01.04.2021).

7. Портал Национального исследовательского университета «МЭИ» ГЭлектронный pecypc] / Научные группы. - Режим доступа: https://mpei.ru/Science/ScienseGroup/Pages/ default.aspx/ (Дата обращения: 01.04.2021).

8. Костин Р.С. Организационно-экономический механизм управления рисками инновационной деятельности предприятий: дис. ... канд. экон. наук: 08.00.05 / Костин Роман Сергеевич. - Санкт-Петербург, 2017. $167 \mathrm{c}$.

9. Киселева М.А. Модель управления научно-исследовательской деятельностью национальных исследовательских университетов// Экономика и управление в машиностроении. - 2019. - №5. - С. 10-14.
10. Киселева М.А. Структурная модель процесса разработки и реализации принятия эффективных управленческих решений по выбору субъектов научно-исследовательской деятельности // Креативная экономика. - 2020. - Т. 14. — №11.

11. Арнаут М.Н. Организационно-экономический механизм управления устойчивым развитием университета: дис. ... канд. экон. наук: 08.00.05 / Арнаут Марина Николаевна. - Владивосток, 2014. - 189 с.

12. Пономарева Е.В. Методология проведения pestel-анализа / Е.В. Пономарева // Научный журнал «Экономика и социум». 2016. — №11-2 (30). — С. 264-270.

\section{References}

1. Strategija prostranstvennogo razvitija RF na period do 2025 g. (utverzhdena rasporjazheniem Pravitel'stva RF №207-r ot 13.02.2019) [The strategy of spatial development of the Russian Federation for the period up to 2025 (approved by the decree of the Government of the Russian Federation №207-r of 13.02.2019)] // Spravochno-pravovaja sistema «Konsul'tant Pljus» [Reference and legal system «Consultant Plus»].

2. Federal'naja sluzhba gosudarstvennoj statistiki [Federal State Statistics Service] [Jelektronnyj resurs] / Priznaki NIU [Signs of the National Research University]. — URL: http:// www.edu.ru (Date accessed: 25.03.2021).

3. Portal Novgorodskogo gosudarstvennogo universiteta imeni Jaroslava Mudrogo [Portal of the Yaroslav-the-Wise Novgorod State University] [Jelektronnyj resurs] / Nauchnye gruppy [Scientific Groups]. — URL: https://www.novsu.ru/ (Date accessed: 01.04.2021).

4. Portal Moskovskogo tehnicheskogo universiteta imeni N. Je. Baumana [Portal of the Bauman Moscow Technical University] [Jelektronnyj resurs] / Nauchnye gruppy [Scientific Groups]. - URL: https://bmstu.ru/ (Date accessed: 01.04.2021).

5. Portal Moskovskogo aviacionnogo instituta (nacional'nyj issledovatel'skij universitet) [Portal of the Moscow Aviation Institute (National Research University)] [Jelektronnyj resurs]/ Nauchnye gruppy [Scientific Groups]. URL: https://mai.ru/common/ (Date accessed: 01.04.2021). 
6. Portal Nacional'nogo issledovatel'skogo jadernogo universiteta MIFI [Portal of the National Research Nuclear University $\mathrm{MEPhI}]$ [Jelektronnyj resurs] / Nauchnye gruppy [Scientific Groups]. — URL: https://mephi.ru/sveden/ common (Date accessed: 01.04.2021).

7. Portal Nacional'nogo issledovatel'skogo universiteta «MJeI» [Portal of the National Research University «MPEI»] [Jelektronnyj resurs]/ Nauchnye gruppy [Scientific Groups]. - URL: https://mpei.ru/Science/ScienseGroup/Pages/default.aspx/ (Date accessed: 01.04.2021).

8. Kostin R.S. Organizacionno-jekonomicheskij mehanizm upravlenija riskami innovacionnoj dejatel'nosti predprijatij: dis. ... kand. jekon. nauk: 08.00.05 [Organizational and economic mechanism of risk management of innovative activity of enterprises: Cand. Sci. (Economy) diss.: 08.00.05] / Kostin Roman Sergeevich. - Saint Petersburg, 2017. — 167 p.

9. Kiseleva M.A. Model' upravlenija nauchno-issledovatel'skoj dejatel'nost'ju nacional'nyh issledovatel'skih universitetov [Model of management of research activities of national research universities] // Jekonomika i upravlenie $\mathrm{v}$ mashinostroenii [Economics and Management in mechanical engineering]. — 2019. - №5. Pp. 10-14.

10. Kiseleva M.A. Strukturnaja model' processa razrabotki i realizacii prinjatija jeffektivnyh upravlencheskih reshenij po vyboru sub'ektov nauchno-issledovatel'skoj dejatel'nosti [Structural model of the process of development and implementation of effective management decisions on the choice of subjects of research activity] // Kreativnaja jekonomika [Creative Economy]. — 2020. — Vol. 14. — №11.

11. Arnaut M. N. Organizacionno-jekonomicheskij mehanizm upravlenija ustojchivym razvitiem universiteta: dis. ... kand. jekon. nauk: 08.00.05 [Organizational and economic mechanism of management of sustainable development of the university: Cand. Sci. (Economy) diss.: 08.00.05] / Arnaut Marina Nikolaevna. Vladivostok, 2014. - $189 \mathrm{p}$.

12. Ponomareva E. $V$. Metodologija provedenija pestel-analiza [Methodology of conducting pestel-analysis] / E. V. Ponomareva // Nauchnyj zhurnal «Jekonomika i socium» [Scientific journal «Economics and Society»]. — 2016. №11-2 (30). — Pp. 264-270.

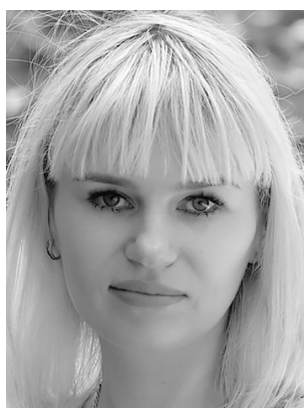

Киселева Мария Андреевна - старший преподаватель кафедры «Менеджмент в энергетике и промышленности» Национального исследовательского университета «МЭИ». Научные интересы: управление персоналом, управление научной и образовательной деятельностью университета.

Kiseleva Maria Andreevna - Senior Lecturer of the Department «Management in Energy and Industry», National Research University «MPEI». Research interests: personnel management, management of scientific and educational activities of the university.

109147, г. Москва, ул. Марксистская, 5, кв. 275

5 Marksistskaya st., app. 275, 109147, Moscow, Russia

E-mail: goldenrose.91@mail.ru 